
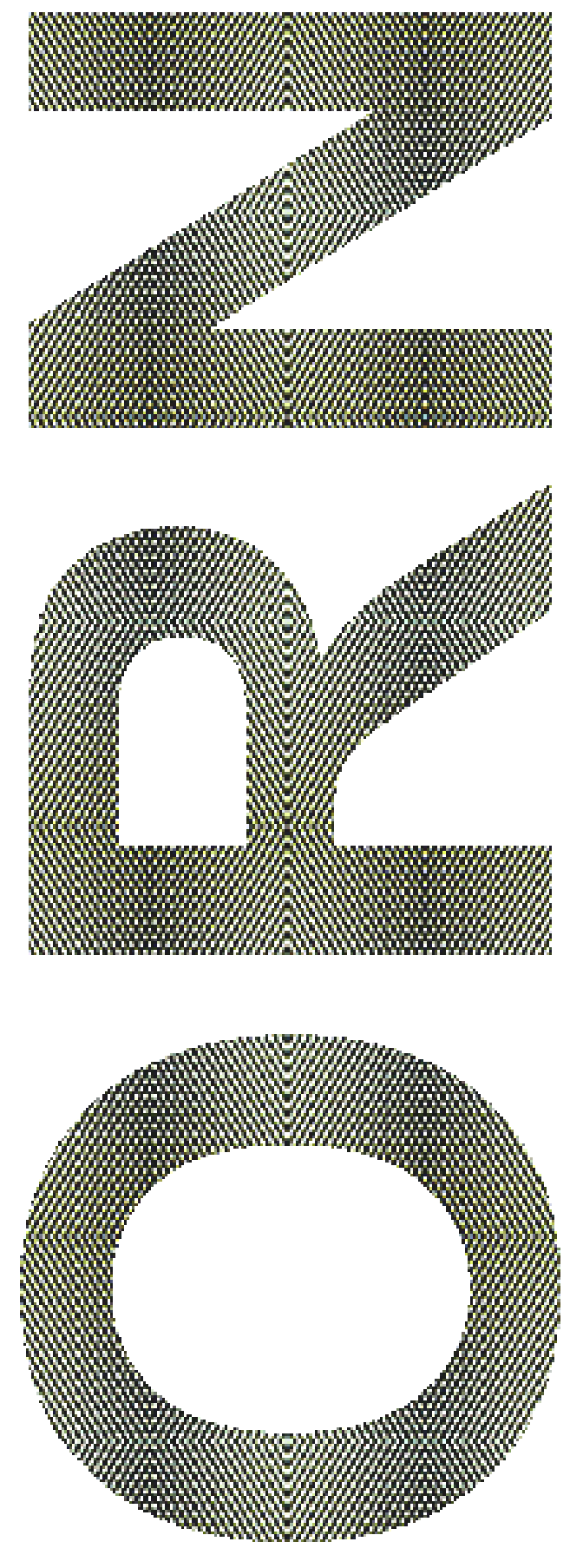

\title{
Economic rationales for the design of health care financing schemes
}

Francesco Paolucci, Frederick T. Scout and Wynand P.M.M. , van de Ven, Department of Health Policy and Management, Erasmus University Rotterdam

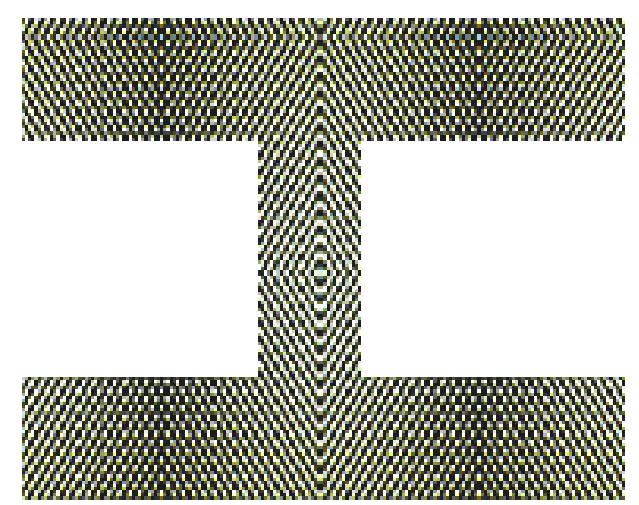

\section{WORKING PAPER 2006:3}

HORN - HEALTH ORgANizATION RESEARCH NORWAY 


\title{
Economic rationales for the design of health care financing schemes
}

\author{
Francesco Paolucci*, Frederick T. Scout and Wynand P.M.M. van de Ven, \\ Department of Health Policy and Management, Erasmus University Rotterdam, \\ The Netherlands
}

18. June 2006

\section{HEALTH ORGANIZATION RESEARCH PROGRAM NORWAY HORN 2006}

HORN Working paper 2006:3

\footnotetext{
*Correspondence to: Francesco Paolucci, P.O. Box 1738, 3000 DR Rotterdam, The Netherlands. Phone: 003110408 8535, Fax: Fax: 0031104089094.

E-mail: paolucci@bmg.eur.nl.
} 


\title{
"Economic rationales for the design of health care financing schemes"
}

Francesco Paolucci ${ }^{1}$, Frederick T. Schut, Wynand P.M.M. van de Ven

\begin{abstract}
In this paper we investigate the economic rationales for the design of health care financing arrangements. We propose a categorization of financing schemes based on a distinction between basic and supplementary services and between mandatory and voluntary coverage. We argue that the most important economic arguments for governments to enforce a system of crosssubsidies that guarantees the financial access to a predefined set of basic services to high-risk or low-income individuals are the presence of externalities in health care services consumption; the individuals' risk of becoming bad risks; and the moral hazard effects induced by crosssubsidization. In addition, we argue that the rationale for mandatory coverage is based on considerations of free riding behaviour, individuals' lack of foresight and too high transaction costs of alternative ways to organize crosssubsidies.

Finally, we will discuss the implications of our analysis for the design of health care financing arrangements.
\end{abstract}

\section{Introduction}

\footnotetext{
${ }^{1}$ Department of Health Policy and Management, Erasmus University Rotterdam, The Netherlands

Correspondence to:

Francesco Paolucci, P.O. Box 1738, 3000 DR Rotterdam, The Netherlands.

Phone: 003110408 8535, Fax: 0031104089094.

E-mail: paolucci@bmg.eur.nl.
} 
In general, health care financing schemes may be distinguished according to the type of services (basic or supplementary) and the type of coverage (mandatory or voluntary) they provide. The structure of these schemes differs substantially across countries and it has been exposed to several changes throughout the years. In particular, different countries in different times may categorize services and coverage differently. For example, dental care and physiotherapy are currently considered as basic services in some countries (e.g. Germany) and in others not (e.g. Switzerland). Or they once were considered as basic services but not nowadays (e.g. the Netherlands). Countries may also differ in the speed with which new therapies and pharmaceuticals are considered as basic services and whether to impose mandatory coverage. The political decisions about which services should be considered as basic and whether coverage should be mandatory may change in time (time-dependent) and differ across diverse communities or countries (community-dependent).

In most countries, the decisions concerning the categorization of services and coverage are based on a number of "implicit" value judgments. For instance, society's choice regarding the inclusion or exclusion of services in the basic basket $^{2}$ implicitly involves judgments about individuals' willingness to participate in a system of cross-subsidies (solidarity) that aims at guaranteeing financial access for the majority of the population. In the following sections, the focus is not on the ethical or political aspects of such "implicit" judgments, but rather on the set of economic arguments that may underlie these judgments. For this purpose, a general framework is developed that analyses the main economic rationales underlying the political choice of categorizing services in basic and supplementary and coverage in mandatory and voluntary. In particular, the following question is addressed:

- What can be the economic arguments for categorizing health care services in basic and supplementary, and coverage in mandatory and voluntary?

2 The basic basket (or package) represents the totality of basic services. 
In the categorization of health care services other criteria may also be advocated such as legal, historical (i.e. path dependency), and political (i.e. pressure groups) etc., however here the focus is on the economic rationales.

This paper is structured as follows. In section 2, we provide the main definitions adopted in the conceptual framework and throughout the thesis. Section 3 and 4 deal with the economic arguments for governments to categorize services in basic and supplementary, and coverage in mandatory and voluntary. The main conclusions are summarized in section 5 .

\section{Defining health care financing schemes}

The great variety of definitions used in the literature (see for example Colombo, 2004) to describe the diverse health care financing arrangements in different countries requires some preliminary clarification. We envisage two essential dimensions for defining different health care financing arrangements: 1) the type of services and 2) the type of coverage they provide. By services we mean health care goods and services, ${ }^{3}$ and by coverage we refer to the guarantee of financial access to predefined health care services. Coverage may be either in-kind or in-cash.

In this thesis, we distinguish between basic and supplementary services, and between mandatory and voluntary coverage. Historically in most countries the crucial element of distinction between basic and supplementary services has been cross-subsidization. Therefore, basic services ${ }^{4}$ are defined as the set of health care services for which the government guarantees the financial access for the high risk and/or low income groups, by enforcing a system of cross-subsidies from low to high risk groups or from high to low income

\footnotetext{
${ }^{3}$ In insurance the term benefits is widely adopted in the literature to refer to health care services and goods. Throughout this thesis the term benefits is sometimes preferred, particularly when referring to services provided by insurance schemes or contracts.
} 
groups. ${ }^{5}$ Supplementary services are defined as the set of health services that do not fulfill the conditions for being considered as basic.

Then, the term basic health insurance (BHI) refers to schemes that provide coverage to basic health care services within a certain Society. Supplementary health insurance (SHI) refers to those schemes covering supplementary services, which are by definition excluded from BHI.

We define mandatory coverage if the government imposes on consumers a legal obligation to obtain coverage. By contrast, we refer to voluntary coverage when people are free to decide for which services to cover. Restrictions on choice of coverage as a result of employment-based group contracts do not fall under the scope of our definition of mandatory coverage, since these restrictions are not the result of government regulation.

Then, the term mandatory health insurance (MHI) refers to schemes that provide mandatory coverage for either basic or supplementary services. In case these services are basic we refer to mandatory basic health insurance, if they are supplementary we refer to mandatory supplementary health insurance. In case there is no legal obligation set by the government limiting consumers' choice of coverage, we are in presence of voluntary health insurance (VHI), which may provide coverage for either basic or supplementary services (see Table 1 ).

(Table 1 about here)

Table 1. Defining health insurance schemes.

\footnotetext{
${ }^{4}$ It is implicitly assumed that individuals are in need of the health care service, on the basis of a specific medical indication or range of diagnosis.

5 Subsidies may be allocated to finance directly basic services' provision or to finance the coverage for these services. Health care systems, in which subsidies are allocated to finance directly the purchase of basic services' provision, are usually identified as National Health Insurance or Service (NHI or NHS) schemes. In case the subsidies finance the purchase of basic services' coverage, the health care systems are usually identified as Social Health Insurance.
} 


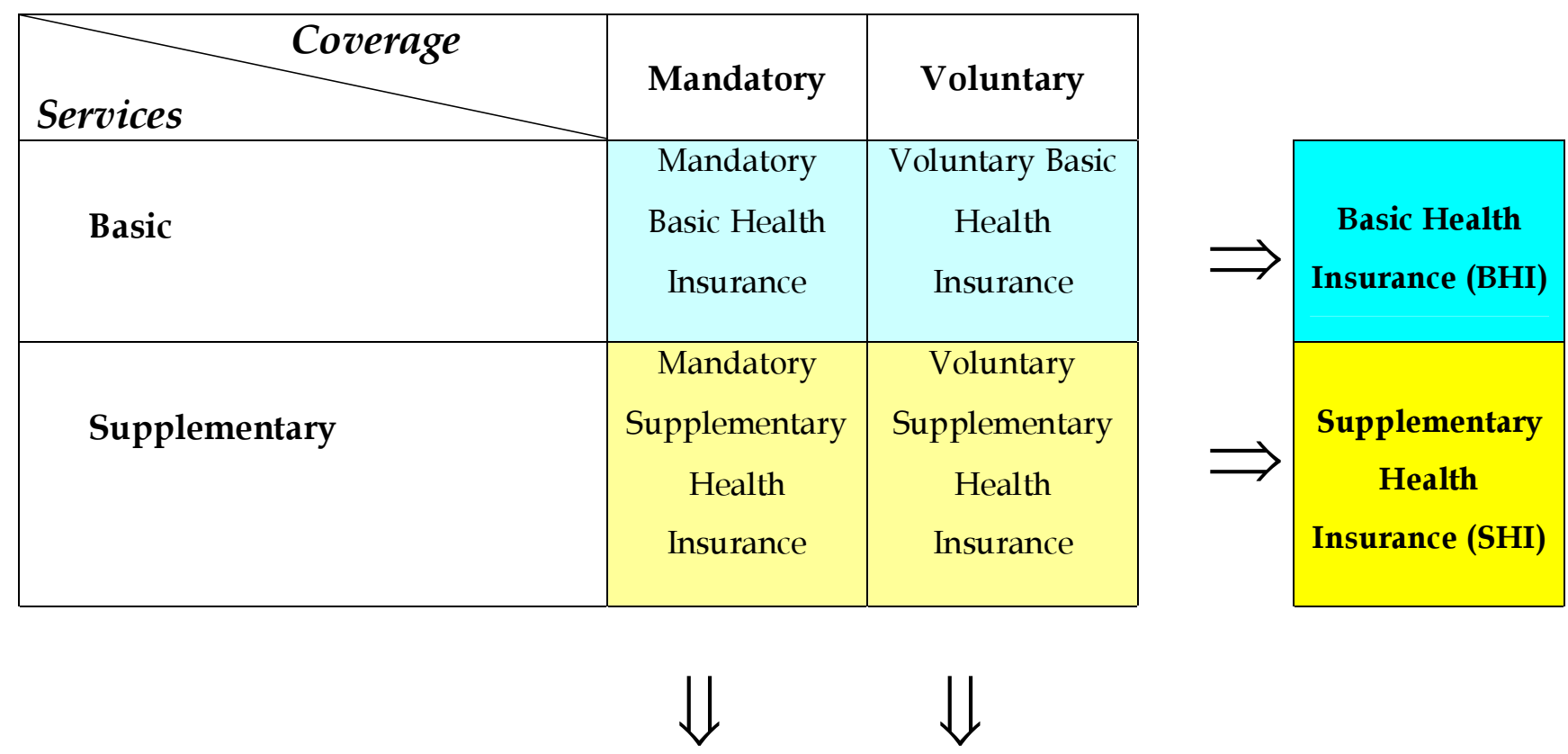

\begin{tabular}{|c|c|}
\hline Mandatory & Voluntary \\
Health & Health \\
Insurance & Insurance \\
(MHI) & (VHI) \\
\hline
\end{tabular}

\section{Categorizing services in basic and supplementary}

In most societies individuals appear to be willing to support a system of crosssubsidies that guarantees the financial access to basic services for the high risks and/or the low income groups. In order to assure the existence and the functioning of the cross-subsidy system government intervention may be required. For instance, governments' enforcement of a mandatory crosssubsidy system may be necessary to prevent that some individuals free ride on the contributions by others. ${ }^{6}$ In this section, we discern the main economic

6 Theoretically, government intervention would not be necessary if the individuals' willingness to cross-subsidize overwhelms the incentives for free riding. Empirical evidence concerning the importance of the free rider problem in public good provision is not conclusive. The results from a study by Palfrey and Prisbrey (1997) seem fairly typical. On 
arguments for governments to enforce a system of cross-subsidies that guarantees the financial access to basic services for the high risks and/or the low income groups. In particular, we distinguish and discuss the following economic arguments: the presence of externalities in the demand for some health care services (section 3.1.), the individual's risk of becoming a high risk (section 3.2.), and the moral hazard effect induced by cross-subsidization (section 3.3.).

\subsection{Externalities}

For some goods and services, including many forms of medical treatment, consumers may be willing to pay for the consumption by others. A reason for this is that the consumption of health care services produces external effects. Externalities arise when a consumption (production) activity of one set of individuals affects the utility functions of other individuals, while this effect is not included in the individuals' utility functions. In other words, externalities occur when the activities of an individual produce results that affect others but are not taken into account by those who produce them. Externalities can be both positive and negative. Positive (negative) externalities occur when actions of one set of individuals make other individuals better (worse) off, yet the first set neither bear the costs nor receive the benefits of doing so (Gruber, 2005). The external effects generated by an individual's non-consumption of health care services' are mainly the consequence of two types of interpersonal preferences: altruistic and egoistic preferences. The literature (Culyer \& Simpson, 1980; van Doorslaer \& Schut, 1999) tracks down a third type of interpersonal preferences so-called paternalistic preferences. Since the only

\footnotetext{
average, people contribute only a portion of their resources to the provision of the public good, suggesting the existence of some free riding. On the other hand, the results contradict purely calculating behaviour in which case free riding would lead to zero or trivial amounts of a public good. Two other important results are that the more people repeat the game, the less likely they are to contribute, and that the contribution rates decline when the opportunity cost of giving goes up. Brunner (1998) found evidence suggesting the existence of a subset of public goods for which an increase in the number of users does not decrease the users' willingness to contribute to the financing of that good.
} 
difference between paternalistic and altruistic preferences is in the extent and the focus of an individual's concern about others, we simply distinguish between two types of altruistic preferences. We refer to type-1 altruistic preferences if an individual's concern is about others' general wellbeing and to type-2 altruistic preferences if an individual concerns specifically about others' health status.7

\subsubsection{Altruistic preferences ${ }^{8}$}

A first important consumption externality in health care is the presence of type-1 altruistic preferences that is an individual's concern about the wellbeing of others. Thus, individuals' concern about others' well-being generates an altruistic externality which calls for subsidization. Type-1 altruistic preferences may undertake a very general form of interpersonal dependencies. For instance, the interpersonal utility function for individual B may look like the following:

$$
\mathrm{U}_{\mathrm{B}}=\mathrm{U}_{\mathrm{B}}\left(\mathrm{H}_{\mathrm{B}}, \mathrm{U}_{\mathrm{A}}\left[\mathrm{H}_{\mathrm{A}}\left(\mathrm{M}_{\mathrm{A}}\right), \mathrm{C}_{\mathrm{A}}\right], \mathrm{C}_{\mathrm{B}}\right)
$$

The utility of B is in this case a direct function of the utility of individual A and therefore of $\mathrm{A}^{\prime}$ s health status $\left(\mathrm{H}_{\mathrm{A}}\right)$ and health care consumption $\left(\mathrm{C}_{\mathrm{A}}\right)$. An important implication of this model is that $B$ respects the preferences of A. For example, if A prefers other goods $\left(\mathrm{C}_{\mathrm{A}}\right)$ over health or health care, than $\mathrm{B}$ may also be willing to pay for $A^{\prime}$ s consumption of these other goods $\left(C_{A}\right)$. Therefore, A freely chooses, based on his/her own preferences, whether to consume medical care $\left(\mathrm{M}_{\mathrm{A}}\right)$ or other goods $\left(\mathrm{C}_{\mathrm{A}}\right)$. A financial transfer of income

\footnotetext{
7 The social concern for the distribution of the use of health care services may be based on viewing medical care as involving good-specific altruism (Diamond, 1992) or commodityegalitarism (Evans, 1978).

${ }^{8}$ In this paper, we do not deal with the question: what determines altruism? This question has given rise to an entire field of study of social capital, the value of altruistic and communal behaviour in society. A central finding of this field is that individuals are likely to be more altruistic when they are more "trusting" others. Anderson et al. (2003) found that most of the
} 
(lump sum) from B to A would appear to be the simplest transaction in order to increase $\mathrm{A}^{\prime}$ s utility. ${ }^{9}$

Alternatively, an individual's concern about others may not be focused on others' general wellbeing but specifically on their health status (type-2 altruistic preferences). In other words, an individual may prefer to contribute to improvements in others' health status rather than others' general welfare (Arrow, 1963; Reinhardt, 1998). In this case, type-2 altruistic preferences may be expressed by the following interpersonal utility function for individual B:

$$
\mathrm{U}_{\mathrm{B}}=\mathrm{U}_{\mathrm{B}}\left(\mathrm{H}_{\mathrm{B}}, \mathrm{H}_{\mathrm{A}}\left(\mathrm{M}_{\mathrm{A}}\right), \mathrm{C}_{\mathrm{B}}\right)
$$

The utility of $B$ is a direct function of A's health status $\left(\mathrm{H}_{A}\right)$, therefore B's willingness to subsidize limits itself to A's medical consumption, in so far that it positively contributes to $\mathrm{A}^{\prime}$ s health status. Possible interpersonal transactions, which could increase the utilities of both individuals, would have to be income- or risk-related subsidies earmarked to the consumption of specific services that positively contribute to health. Most people seem to be unwilling to deny effective care to other members of society. ${ }^{10}$ Presumably, an individual's concern toward others' health status does not only depend on the effectiveness of treatments, but also on the costs and the severity of the illness. For instance, in case of lifesaving interventions individuals may be willing to cross-subsidize the financial access of high-risk or low-income individuals to services or treatments, even if they are not particularly cost-effective. Thus,

attitudinal and behavioural measures of trust were positively correlated with high contributions to merit or public goods.

9 The problem with this "lump-sum solution" is the virtual impossibility of establishing lump-sum taxes and subsidies that do not affect incentives of either the payer of the tax or the recipient of the subsidy (Graff, 1971; Nath, 1969; Samuelson, 1947).

${ }^{10}$ Van den Berg et al. (1986) found evidence of the presence of strong altruistic preferences for medical care consumption in the Netherlands. From data of the 1985 Health Interview Survey by the Netherlands Central Bureau of Statistics (CBS) they conclude that $78 \%$ of the representative sample population fully disagreed with the statement that 'people with a less favorable health status should pay more for health care than people in good health' $(9 \%$ partially agreed, only $3 \%$ fully agreed and $10 \%$ had no opinion). 
altruistic preferences may be stronger for some health care services than for others.

Given the presence of altruistic preferences, an individual's utility of supporting a system of cross-subsidies that guarantees the financial access to health care services by others may depend on various factors, such as the costeffectiveness of services, the initial health status, the expected cost of services per consumer, and the consumers' responsibility for the incidence of the disease. Each of these factors will be discussed below.

\section{Cost-effectiveness of services}

Cost-effectiveness analyses (CEA) are usually indicated as the primary tools policy-makers adopt in deciding whether to include (or exclude) a service in the basket (Drummond et. al., 1997). ${ }^{11}$ In CEA the costs of alternative services are their health effect which may differ in magnitude between the alternative services. The results of a CEA are summarized by the cost-effectiveness (CE) ratio. ${ }^{12}$ The $C E$ ratio compares the incremental cost of an intervention with the incremental health improvement attributable to the intervention. The health improvements of using the intervention are typically measured in qualityadjusted life-years (QALYs) gained. Therefore, the CE ratio is usually expressed as a cost per QALY gained. ${ }^{13}$ The intervention with the relatively lower CE ratio is considered the most cost-effective. In other words, CE ratios

\footnotetext{
11 An extensive literature review about CEA methodology may be found elsewhere (Hauck et al., 2003). Key problems include choice of a summary measure to capture other benefits important to patients and the public; non-comparability of the values elicited with different health state value elicitation instruments; generalizability of studies beyond the study setting or country; choice of target population receiving the intervention; accounting for uncertainty in measuring costs and outcomes; inability to account for the opportunity costs of the costincreasing element of new interventions; and the requirement to consider portfolios of programmes, rather than individual technologies.

12 Let the subscripts 1 and 0 denote the intervention under study and the alternative to which it is compared, respectively. If $C_{1}$ and $C_{0}$ are the net present values of costs that result when the intervention and alternatives are used, and $E_{1}$ and $E_{0}$ their respective health outcomes, the incremental CE ratio is simply: $\mathrm{CE}$ ratio $=\left(C_{1}-C_{0}\right) /\left(E_{1}-E_{0}\right)$. This ratio, which is a cost per unit incremental health effect, is often used as a measure of value.

${ }^{13}$ In many respects QALYs are analogous to life expectancy, but include interventions that improve quality of life even when they do not affect survival. Each year that an individual lives longer contributes an additional year to the life expectancy calculation. The amount that
} 
indicate which health care services will provide health improvements most efficiently (i.e. at a lower cost) (Garber, 2000).

The information provided by CE ratios may affect an individual's utility of contributing to a system of cross-subsidies, since they allow comparisons among different services in terms of costs and effects (i.e. measured in QALYs). In particular, economically rational individuals with altruistic preferences maximize their utility by maximizing the effect of cross-subsidies on others' health status. The effect of cross-subsidization on others' health status increases with the cost-effectiveness of the treatment. The more costeffective the services are the more effective cross-subsidization on others' health status is, and thereby the more the altruistic preferences of rational individuals are satisfied. All in all, the utility of a rational individual with altruistic preferences increases with the cost-effectiveness of health care services. The higher the cost-effectiveness of an intervention for a specified diagnosis, the higher an individual's utility of contributing to a system of cross-subsidies that guarantees the financial access to the intervention by others.

\section{Initial health status}

For many decades, cost-effectiveness analysis (CEA) has been commonly advocated as the prime economic method for priority setting. Despite the refinement of the technical and methodological issues arising from the use of economic evaluation in priority setting, decision makers continue to diverge frequently from the principles of economic evaluation (Stolk et al., 2002; and Goddard et al., 2006). In particular, cost-effectiveness information is not the only grounds on which individuals' altruistic preferences are based, and thereby for governments to decide whether a certain service should be

each additional year of life adds to QALYs, in contrast, is a preference weight or utility that takes a value between 0 (death) and 1 (best health imaginable). 
considered basic or supplementary. ${ }^{14}$ For instance, in the case of lung- or heart-transplants, a relatively low cost-effectiveness does not appear to constitute a sufficient motivation to consider these services as supplementary in most countries. A parallel argument can be made for Viagra, which is not included in the basic basket of most countries despite its high costeffectiveness.

Apparently, when it comes to assess whether and to what extent specific health care services generate altruistic externalities, other factors, besides costeffectiveness, such as the individuals' initial health status have to be considered..$^{15}$ The basic hypothesis of the initial health status approach presented here is that an increase in an individual's utility produced by an improvement of a given size in others' health status is greater the lower the patient's initial health status (Figure 1 about here).

\footnotetext{
14 Also Goddard et al. (2006) argue that despite the refinement of the technical and methodological issues arising from the use of economic evaluation in priority setting, decision makers continue to diverge frequently from the principles of economic evaluation.

15 Although related to the argument of individuals' initial health status, the concepts of severity of illness (Nord et al., 1999), fair inning (Williams, 1997) and proportional shortfall (Johannesson, 2001; Stolk, 2004) will not be discussed, since they do not explicitly refer to the variation in an individual's utility of supporting a system of cross-subsidies generated by an improvement in others' health status or quality of life.
} 


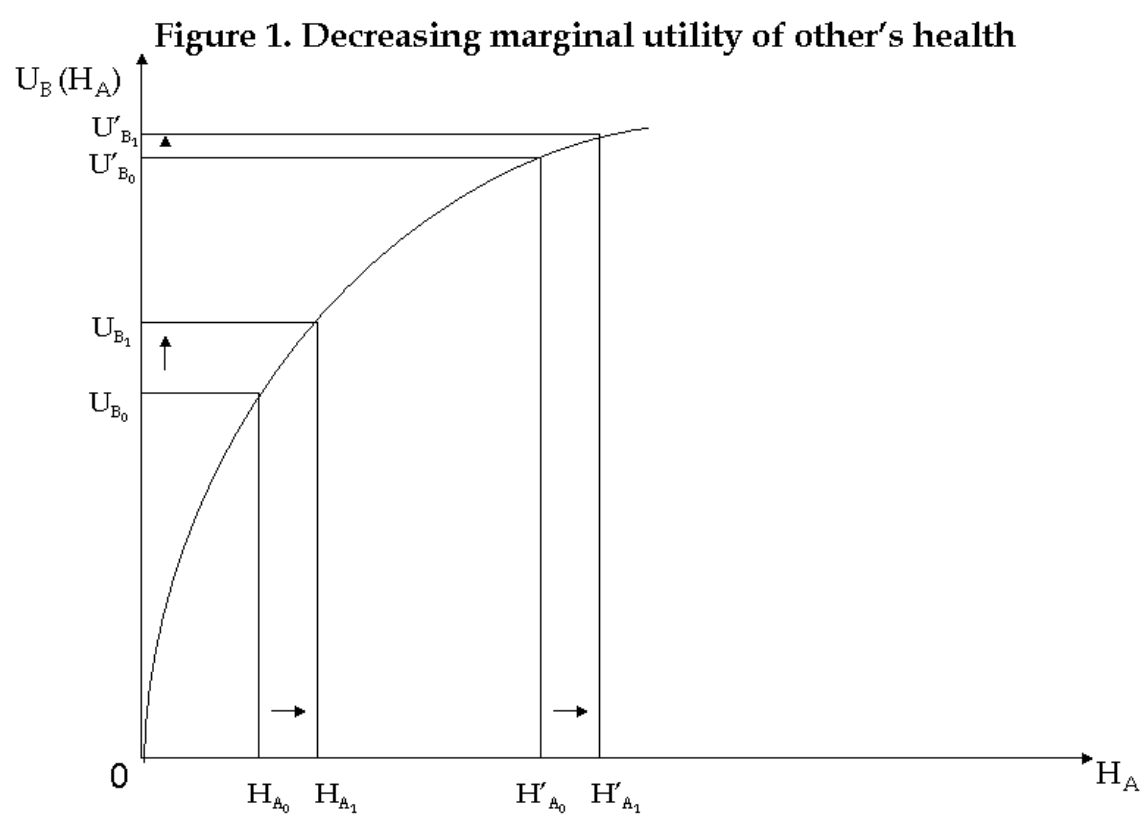

In general, an individual's marginal utility of his or her "own" health is likely to decrease as his or her "own" health status improves i.e. an improvement on an individual's "own" health status increases his or her "own" utility more the lower his or her "own" health status. This is also likely to hold for the marginal utility of "other's" health. The assumption of decreasing marginal utility of "other's" health implies that for equal improvements on A's health status $\left(\mathrm{H}_{\mathrm{A} 1}-\mathrm{H}_{\mathrm{A} 0}=\mathrm{H}^{\prime}{ }_{\mathrm{A} 1}-\mathrm{H}^{\prime}{ }_{\mathrm{A} 0}\right)$, the difference in $\mathrm{B}^{\prime} \mathrm{s}$ utility decreases the higher is $A^{\prime}$ s initial health status $\left(\mathrm{U}^{\prime}{ }_{B 1}-\mathrm{U}^{\prime}{ }_{\mathrm{B} 0}<\mathrm{U}_{\mathrm{B} 1}-\mathrm{U}_{\mathrm{BO}}\right)$. More precisely:

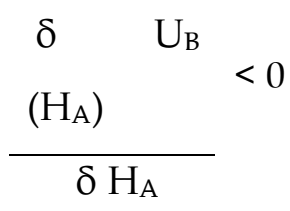

Therefore, the assumption of decreasing marginal utility of "other's" health implies that an individual's marginal utility of supporting a system of crosssubsidies that guarantees the financial access to specific services is greater the lower others' initial health status. Everything equal, the poorer the initial 
health status (measured in QALYs) of a patient, the more the effect of crosssubsidies is satisfying an individual's altruistic preferences.

In current CEA, health improvements (i.e. gains in QALYs) produced by consumption of health care services are weighed equally regardless the initial health status of patients. Thus, only the number of QALYs gained determines priority, while in a decision-making process of a rational altruistic individual QALYs that are gained by people with a lower initial health status may be given more weight. For instance, patients eligible for a lung transplant normally are in such poor health states (in Figure 1 closer to 0 on the $X$ axis, i.e. $\mathrm{H}_{\mathrm{A} 0}$ ), that altruistic individuals may find it acceptable to cross-subsidize the high cost per QALY in order to provide patients with a 'last resort medicine'. This phenomenon may be especially pronounced for lifesaving interventions. In contrast, erectile dysfunction is generally considered to be a minor health problem. Since it generally occurs to people with good health status (in Figure $1 \mathrm{H}_{\mathrm{A} 1}$, i.e. high initial health status), the QALY gains produced by Viagra, which is a cost-effective treatment, would receive a relatively low weight. Note that in specific patient groups such as patients with erectile dysfunction due to spinal cord injuries, this argument does not hold, since these patients' initial health status is low. Therefore, a rational altruistic individual may be willing to cross-subsidize the low cost per QALY of Viagra to patients with a diagnosed erectile dysfunction due to spinal cord injuries.

In deciding whether or for which diagnosis a service may be classified as basic or supplementary, the use of weights that consider the cost-effectiveness of services and the initial health status of patients would reflect the individuals' altruistic preferences. 
A rational and altruistic individual's utility of supporting a system of crosssubsidies may also be affected by the expected costs of health care services faced by others. Being all other things equal, the lower the expected cost of services per consumer the weaker the effect of cross-subsidies is likely to be in satisfying an individual's altruistic preferences. In general, a system of crosssubsidies satisfies an individual's altruistic preferences, and thereby it produces a welfare gain, in so far that it increases the financial access to otherwise unaffordable care (Nyman, 2003). Whether and to what extent health care is un-affordable may vary across individuals, and it depends in particular on their available income (or total wealth). For instance, if services involve low utilization rate and are relatively cheap (i.e. Paracetamol), an individual may not be willing to cross-subsidize people who need them, given that these services may be easily accessed without constituting an excessive financial burden on each consumer. Nevertheless, there always are individual consumers for whom even low prices or volumes are hard to sustain autonomously, and the absence of subsidies may cause differences in health care use. These differences may generate altruistic externalities for some health care services, and thus call for subsidies.

Ceteris paribus, the higher the expected price and volume of medical care per consumer, the greater an individual's utility of contributing to a system of cross-subsidies, and thereby the stronger governments' arguments to enforce it.

Consumer's responsibility for the incidence of the disease

Another factor that may influence an individual's willingness to support a system of cross-subsidies can be derived from a consumer's responsibility in originating the condition for which services are demanded. Consider the case of health care expenditures, which clearly depend on the individuals' responsibility or behavior, such as smoking or skiing accidents. For example, 
individuals may be more inclined to subsidize for Viagra for somebody with an erectile dysfunction due to a spinal cord injury resulting from a traffic accident, than for someone with an erectile dysfunction due to excessive smoking. Skiing accidents may require the use of several health care services (i.e. transportation from the ski run to the hospital), whose consumption by skiers may generate no or little external effect on non-skiers.

All in all, the greater a consumer's responsibility in originating a condition is, the less would the use of services satisfy altruistic preferences, and thereby the lower an individual's utility to support cross-subsidization for the consumption of the services. In practice, however, it may be difficult to prove the connection between someone's responsibility and health care consumption. And, even if so, it may be practically unfeasible to set-up a system of cross-subsidies that corrects for it.

\subsubsection{Egoistic preferences}

Externalities generated by the individual's (non-)consumption of health care services may be the consequence of egoistic preferences. For instance, individual B may be concerned about the use of medical care by individual A simply for egoistic reasons such as in the case of communicable diseases. The interpersonal utility functions for B looks like the following:

$$
\mathrm{U}_{\mathrm{B}}=\mathrm{U}_{\mathrm{B}}\left(\mathrm{H}_{\mathrm{B}}\left[\mathrm{M}_{\mathrm{B}}, \mathrm{H}_{\mathrm{A}}\left(\mathrm{M}_{\mathrm{A}}\right)\right], \mathrm{C}_{\mathrm{B}}\right)
$$

The medical consumption of $A\left(M_{A}\right)$, for example in the form of vaccination, reduces the chances that $\mathrm{A}$ gets a communicable disease and improves, in that way, the health of $A\left(\mathrm{H}_{\mathrm{A}}\right)$. However, because of the existence of a chance that B will also be infected by A (external effect), this has an influence on the (expected) health of $B\left(\mathrm{H}_{B}\right)$, and thereby on $B^{\prime}$ s utility $U_{B}$. In general, immunization for communicable diseases yields a positive utility for all non- 
immunized individuals. ${ }^{16}$ This externality limits itself to the use of few health care services, for which there is a divergence between collective and individual benefits or costs of consumption (Schut and Lapre', 1988; Schut, 1995). Suppose that the full cost of immunization is borne by each consumer then the risk of underconsumption is likely to occur, that is individuals may purchase less of these services than the socially optimal level. ${ }^{17}$ In fact, rational consumers would purchase goods until the ratio of the marginal utility of each to its price is equal across all goods. Therefore, when there is a positive consumption externality, the collective marginal utility is greater than that of the individual, so that (some) consumers, acting on their own and relying on their own resources, will not buy a large enough quantity of such goods (Rice, 2003). The risk of underconsumption is higher for low-income individuals, because high-income people have higher opportunity costs of getting medical care and lower marginal utility of money. In the case of a positive externality, a straightforward way to overcome underconsumption is to introduce subsidies. ${ }^{18}$ If a large number of people benefits from the subsidies, as it appears to be the case for immunizations, it is very likely that most individuals would also be willing to participate in a system of subsidies. Another consumption externality in health care is the presence of individuals' concern about their own status relative to others. Therefore, individuals' utility depends not so much on what they have in absolute terms but relative to others (Rice, 2003). Most plausible, perhaps, would be that people want those who have less than they have to have more (altruistic preferences) and,

\footnotetext{
16 Similarly, effective preventive care may generate positive externalities. The consumption of effective preventive care may constitute a net gain for society as a whole, since it may reduce the chance of using more costly curative services in the future. This holds true if society pays for the future costs of curative services.

17 The demand for preventive care is likely to be less than socially optimal because of the fact that moral hazard results in a substitution away from preventive care toward curative care (Pauly, 1974). The gains from preventive care are uncertain and occur in the future, while the costs (in terms of money and time) have to be made in advance. By contrast, curative care often offers a short-term and more certain gain. Therefore, the stronger the individual's asymmetry with respect to uncertainty surrounding gains and losses, the less likely the person will demand preventive care (Fuchs, 1982).
} 
at the same time, want to have as much as those who have more (concern about status or rank). Yet economists usually assume that utility is a function of an individual's endowment, independent of his relative position. The importance of relative standing, or positional externalities, has a long history in economic theoretical (Veblen, 1899; Duesenberry, 1949; Galbraith, 1958) and empirical analysis (Duncan, 1976; Kapteyn et. al., 1985; Neumark, 1993; Easterlin, 1995). Positional ${ }^{19}$ externalities occur when “one person's action alters an important frame of reference for others" " (Frank, 1991). People care about their relative position in society for many reasons. One of these reasons might be that people feel envy when others have things that they themselves do not possess. Envy may create distortions in individuals' utility functions and its presence raises important policy questions (Frank, 1985; Bannerjee, 1990; Elster, 1991; Choi, 1993). ${ }^{20}$ For example, the use of cosmetic treatments such as facelifts by some individuals may result in a reduction of the utility for the others since their look may be no longer as appealing. Then society's marginal utility from the consumption of cosmetic treatments will be lower than the individual marginal utility of the facelifts' users. Moreover, the concern for great relative physical attractiveness can lead everyone to expend resources simply to remain in the same relative position (Wolf, 1991). Therefore, including cosmetic surgery (or similar services) within the basic basket, may lower the cost borne by individuals, due to cross-subsidies, increase the quantity of services consumed and enlarge the deadweight loss. In order to increase social welfare and correct for this external effect,

\footnotetext{
${ }^{18}$ For instance, governments may enforce a system of earmarked income-related (from high to low income groups) cross-subsidies, or subsidize the provision of immunizations, even providing them free of charge.

19 The term 'positional' has not been applied uniformly in the literature. For instance, positional goods were initially defined, by Hirsch (1976), as those that are in fixed supply or subject to congestion with increased use.

${ }^{20}$ Solnick et. al. (1998) attempt to identify what things create positional externalities and when people may find themselves on a positional treadmill. In other words, they try to answer the question: to what extent are positional externalities imposed when I have e.g. cosmetic surgery? They found that positional concerns are extremely important for physical attractiveness and stronger for goods than for bads.
} 
governments could introduce taxation or leave these benefits out of the basic basket (Frank, 1999).

\subsection{The financial risk of becoming a high risk}

The individuals' risk of incurring high medical costs for future health problems may constitute a second argument for governments to establish a system of cross-subsidies. In particular, the occurrence of catastrophic risks or long-term chronic illnesses, such as AIDS, cancer, senile dementia, heart disease, or organ failure may cause dramatic increases in health expenditures, which are likely to be unbearable by most individuals. The problem faced by consumers, in particular low-income individuals, is that of obtaining lifetime insurance for this type of risks/illnesses (Newhouse, 1984; Diamond, 1992; Pauly, 1992; Cochrane, 1995).

In real-world markets, however, insurance against the financial risk of becoming a high risk is incomplete. Therefore, individuals lose welfare ex ante, since they want insurance against the risk of falling into a worse risk class but they cannot obtain it. More precisely, the welfare loss derives from a missing market for insurance against the chance of being discovered to be high risk. This problem has been termed the problem of renewable insurance or the problem of intertemporal insurance (Cutler et. al., 2000).

In order to correct for this market failure, government intervention may be required. ${ }^{21}$ In particular, by establishing a system of cross-subsidies that increases the financial access for high-risk and/or low-income groups to health care services, governments guarantee that risk-averse consumers are insured against long-term health risks (i.e. dramatic and unforeseen future

\footnotetext{
${ }^{21}$ In theory, markets might develop to deal with the problem posed by lifetime insurance. For a careful review of the main reasons suggesting that market solutions (e.g. long-term insurance, time-consistent insurance contracts) may be poor vehicles for insuring long-term health risks, we refer to Cutler et. al., 2000.
} 
changes in health status). ${ }^{22}$ In this sense a cross-subsidy system also provides insurance against the financial risk of becoming a high risk in the future (van de Ven et. al., 2000).

\subsection{Moral Hazard}

Moral hazard may arise along several dimensions. ${ }^{23}$ In general, moral hazard problems refer to adverse behaviors encouraged by the guarantee of financial protection (i.e. subsidies) against losses caused by the occurrence of adverse events (Gruber, 2005). Since subsidies may reduce the marginal cost of basic health care services borne by the individual, they may result in excessive consumption of these services ('consumer-initiated moral hazard'). ${ }^{24}$ Providers may also be inclined to induce additional demand for services of which they know that the costs are covered by subsidies ('supplier-induced moral hazard'), such as basic services.

The problem of moral hazard or subsidies-induced overconsumption is not uniform across health care services. In particular, the extent to which crosssubsidies induce moral hazard depends on the service's demand priceelasticity and on the interactions between basic and supplementary services. The higher is a service's demand price-elasticity the greater is the subsidiesinduced overconsumption. For instance, the moral hazard effect of crosssubsidizing lung-transplants may be much smaller than cross-subsidizing Viagra. In fact, the number of lung-transplants users may be much smaller

\footnotetext{
${ }^{22}$ After all, the traditional function of insurance is to protect against an adverse event that has not yet occurred (Arrow, 1963).

${ }^{23}$ Moral hazard problems are particularly relevant to the health care sector as contrasted with other sectors, because they emerge from the unequal distribution of information between the parties involved. Insurers and governments have highly imperfect information about the appropriateness of medical diagnoses and treatments. Hence, it is very difficult for them to value the damage caused by a disease and to appraise the costs of treatment. Moreover, they cannot judge whether or not subscribers have taken action to prevent diseases from occurring, which make it hard to relate premiums and subsidies to subscribers' preventive activities (Schut, 1995).

${ }^{24}$ Moreover, individuals may reduce preventive activities to protect health status if they are (to some extent) financially protected against adverse events.
} 
than Viagra consumers and is not likely to vary as much in case of crosssubsidization. In other words, the moral hazard effect of cross-subsidizing lung-transplants seems to be smaller than cross-subsidizing Viagra, because the demand price-elasticity of lung-transplants is likely to be smaller than Viagra's. Ceteris paribus, the smaller is the moral hazard effect of crosssubsidizing a specific service, the stonger may be the governments' arguments to enforce a system of cross-subsidies that guarantees the financial access to that service.

We envisage two main interactions between basic and supplementary services that may be relevant for governments' decision of establishing a system of cross-subsidies to increase the financial access to medical care. Firstly, by removing services from the basic basket that are complementary (i.e. prescription drugs) to remaining basic services (i.e. GP care), the consumption of both subsidized (basic) and non-subsidized (supplementary) services may be reduced. In particular, the price increase resulting by the exclusion of complementary services from subsidization reduces the consumers' demand for these supplementary services, and thereby induces a decrease in the demand of basic services (i.e. negative cross price-elasticities). On the other hand, including complementary services in the basic basket may induce moral hazard in terms of excessive consumption of basic services, since price is reduced by cross-subsidization. To the extent that the decrease (increase) in the consumption of basic services is not socially optimal, the exclusion (inclusion) of complementary services from (in) the basic basket may lead to a welfare loss for society. So, complementary services involve a tradeoff between access to basic services and moral hazard.

A second important interaction may occur if cheap substitutes (i.e. OTC drugs) of remaining basic services are removed from the basic basket. Depending on the type of service, the removal of relatively cheap substitutes may induce a substitution effect towards the remaining more expensive basic services. If the total cost (including the subsidy) of basic services would exceed the cost of these substitutes, this substitution effect may imply a 
welfare loss for society. On the other hand, the inclusion in the basic basket of cheaper substitutes, which may be accessed by most individuals without excessive financial burden, may increase moral hazard. So, the substitution effect induced by a system of cross-subsidization leads to a trade-off between cost-effective substitution and moral hazard.

All in all, cross-subsidization may induce moral hazard problems, which consist of excessive, and thereby suboptimal, consumption of services included in the basic basket. Moral hazard may also lead to health care costs' inflation. ${ }^{25}$ So, to the extent that a system of cross-subsidization increases the incentives for excessive consumption of health care services, there is a tradeoff between access to care and moral hazard. Therefore, when deciding whether to include specific services in the basic basket policy makers have to be aware of the financial consequences of subsidies-induced overconsumption on the budget available for cross-subsidies.

\section{Categorizing coverage in mandatory and voluntary}

Coverage, that provides financial access to predefined health care services, may be particularly beneficial for those at the lower end of the income distribution (Nyman, 2003). However, it is those at the lower end of the income distribution who are most likely not to take out coverage voluntarily (Feldstein, 1999). Governments may stimulate the voluntary purchase of coverage by subsidizing it. In addition or in alternative, governments may impose on consumers a legal obligation to obtain coverage. In this section, the

\footnotetext{
25 In particular, subsidies-induced overconsumption by increasing the costs of a specific service may negatively affect the cost-effectiveness ratio of that service. In many countries (e.g. France, The Netherlands, Norway, United Kingdom, ect.) policy-makers have in some circumstances taken into account the ex-post cost-effectiveness ratio in deciding whether or not to subsidize a service. For instance, cost-effective treatments with a high ex-post costeffective ratio (e.g. selective serotonin reuptake (SSRIs), sildenafil (Viagra) ect.) were (partially) removed from the basic basket. On the other end, treatments not considered costeffective (e.g. ultra-orphan drugs) were subsidized because of their low ex-post impact on the budget available for cross-subsidies (Harris et. al., 2001; Kooijman et. al., 2003; Hughes et. al., 2005).
} 
following economic arguments for governments to enforce mandatory coverage are discussed: free riding (section 4.1.), lack of foresight (section 4.2.) and transaction costs of subsidizing coverage (section 4.3.). ${ }^{26}$

\subsection{Free riding}

In general, any investment in goods or services that has a personal cost but a common benefit may provide incentives for individuals to underinvest, or to invest less than is socially optimal (free rider problem). In this context, free riders are individuals who may not voluntarily purchase socially optimal levels of coverage, given that they expect not to be denied access to medical treatments in case of need. The availability of services financed by others reduces an individual's demand for coverage primarily because it removes the health consequences (i.e. disutility) of being uncovered. If governments do not impose any legal mandate to cover for predefined health care services, individuals may have incentives to free ride.

An individual's incentives and opportunities to free ride may not be homogeneous across different income groups. Suppose that the full cost of coverage for predefined health care services is borne by each individual and

\footnotetext{
${ }^{26}$ In the literature, adverse selection is often advocated as another argument for governments to introduce mandatory coverage (Nyman, 2003). Adverse selection arises when individuals can estimate their expected costs (or risk) more accurately than the insurer. Insurers can counteract adverse selection by trying to obtain information about the applicants' risk, by differentiating the level of coverage to prompt applicants to signal their risk, or by excluding some risks from coverage. These strategies may result in unaffordable high premiums and partial or even absent coverage for specific risk groups. Due to this partial market failure the potential social welfare gain from risk protection cannot be fully realized (e.g. in the US about 40 million people are uninsured). The government can avoid the adverse selection induced welfare loss from inadequate protection by making coverage compulsory. In the presence of mandatory coverage low-risk individuals are prevented from opting out of a pooling equilibrium. But compulsion may generate other welfare losses, i.e. moral hazard. Alternative and less invasive measures deal with adverse selection while maintaining adequate risk protection for all risk groups. The central idea is to require insurers to offer adequate coverage to all applicants, irrespective of risk, while keeping premiums affordable by means of some system to redistribute purchasing power for medical care (Schut, 1995). For instance, governments may introduce a system of (risk-related) cross-subsidies financed via mandatory solidarity contributions which may increase the affordability and sustainability of coverage for high risks.
} 
that access to services is not denied to individuals' without coverage, then the risk of undercoverage may occur. In particular, incentives to free ride increase the lower an individual's available income, because the lower the income the higher the marginal utility of money. In fact, rational consumers purchase goods until the ratio of the marginal utility of each to its price is equal across all goods. Therefore, money saved on not purchasing coverage for health care services may be spent on other goods or services (e.g. food and clothing). Hence, low-income individuals could purposely not cover for health care services because others in society are willing to pay for them if they really need health care. ${ }^{27}$ For high-income people this argument is less relevant because they can (and therefore will have to) pay most health care services themselves. Mandatory coverage also for high-income individuals may be relevant for catastrophic risks with very high expected medical care costs. In fact, the more catastrophic are health risks the greater are the costs of coverage, and thereby the stronger the incentives for purchasing suboptimal levels of coverage.

\subsection{Lack of foresight}

Another argument for governments to enforce mandatory coverage may be based on the concept of individuals' myopic behaviour, implying that individuals do not appropriately cover themselves against health risks. In other words, individuals may fail to maximize their (life-time) utility. For instance, this may mean that consumers feel healthy and underestimate health risks, i.e. young and healthy individuals do not always know what is in their best interest. Individuals may not correctly appreciate how much certain health care services are for their own benefit or for the benefit of their

\footnotetext{
${ }^{27}$ Individuals at the low end of the income distribution may rely on last resort safety nets (e.g. charity), which stand ready to cover for health care services in the event of illness. Empirical studies show that the presence of last resort safety nets, such as charity, reduces the demand
} 
dependents. $^{28}$ Such short-sightedness may lead people to make wrong judgements about the relative importance of certain and direct benefits (i.e. no payments for coverage) compared to uncertain costs. A theoretical explanation to this phenomenon is that individuals' aversion toward risk is not symmetric, since they appear to prefer certain to uncertain gains but prefer uncertain to certain losses (Kahneman \& Tversky, 1979). Therefore, the stronger the individual's asymmetry with respect to uncertainty, the less likely the person will voluntarily demand for coverage.

Individuals' lack of foresight may have serious consequences for individuals and society. In fact, the immediate financial advantage of not paying for coverage may lead to high future expenses, which may be nearly or totally impossible to sustain by individuals. In order to prevent individuals from becoming uninsurable and having unaffordable high health expenditures, government intervention may be required in the form of mandatory coverage. For high-income people this argument is less relevant (although not irrelevant in case of catastrophic health care expenditures) than for low-income people because on average they are better educated and can afford high health expenditures.

Ceteris paribus, the more serious health risks are, the greater the impact of individuals' lack of foresight may be on health expenditures, and thereby the stronger the rationale for governments to introduce a mandatory coverage provision.

\subsection{Transaction costs}

Mandatory coverage, also for the high-income people, can be justified if the transaction costs of organizing otherwise a system of cross-subsidies

for coverage, because they remove the health consequences of being uncovered (Thomas, 1994/5; Cutler et. al., 1996; Dubay et. al., 1997, Holahan, 1997; Johnson et. al., 2000).

${ }^{28}$ We refer, for example, to psycho-geriatric care, to the use of dental care by children, to the contraceptive pill for girls under 18 years old, to long-term psychiatric care, to obstetric care, to long-term nursing home care and to care for persons addicted to alcohol and drugs (van de Ven, 1995). 
(=solidarity) are relatively high. The realization of a system of cross-subsidies involves for example the costs of administering and monitoring the collection of mandatory contributions (e.g. taxes) and the redistribution of subsidies to high-risk or low-income individuals. In case these costs are too high for Society, governments may introduce mandatory coverage for basic services for everyone (i.e. including high-income people). On the other hand, mandatory health insurance may induce moral hazard and increase total health care costs, and thereby constitute a welfare loss for society as a whole. So to the extent that a system of cross-subsidies induces high transaction costs, Society may face a trade-off between moral hazard and transaction costs of cross-subsidies.

\section{Summary and conclusions}

This contribution investigates the economic rationales for the design of health care financing arrangements. It proposes a categorization of financing schemes based on a distinction between basic and supplementary services and between mandatory and voluntary coverage. The most important economic arguments for governments to enforce a system of cross-subsidies that guarantees the financial access to a predefined set of basic services to high-risk or low-income individuals are the presence of externalities in health care services consumption; the individuals' risk of becoming bad risks; and the moral hazard effects induced by cross-subsidization. In addition, the rationale for mandatory coverage is based on considerations of free riding behaviour, individuals' lack of foresight and too high transaction costs of alternative ways to organize cross-subsidies.

The following summary tables $2 \mathrm{a} \& 2 \mathrm{~b}$ present an overview in which the sign and direction of each economic factor is related to the choice basic/supplementary services and the choice mandatory/voluntary coverage.

\section{(Tables 2a \& 2 b about here)}


Table 2a. Economic arguments for categorizing services as basic (supplementary).

\section{Basic Services}

\section{Economic Arguments}

\begin{tabular}{lll}
\hline & CE ratio & $(-)$ \\
\cline { 2 - 2 } & $\begin{array}{l}\text { Initial Health } \\
\text { Status }\end{array}$ & $(-)$ \\
\cline { 2 - 3 } $\begin{array}{ll}\text { Altruistic } \\
\text { Externalities }\end{array}$ & $\begin{array}{l}\text { Expected cost per } \\
\text { consumer }\end{array}$ & $(+)$ \\
\cline { 2 - 3 } & $\begin{array}{l}\text { Consumers' } \\
\text { responsibility for } \\
\text { the incidence of } \\
\text { the disease }\end{array}$ & $(-)$ \\
\hline $\begin{array}{ll}\text { Egoistic } \\
\text { Externalities }\end{array}$ & $\begin{array}{l}\text { Positive } \\
\text { Negative }\end{array}$ \\
\cline { 2 - 3 } $\begin{array}{l}\text { Individual risk of } \\
\text { becoming a bad }\end{array}$ & & $(+)$ \\
\hline
\end{tabular}


risk

\begin{tabular}{lll}
\hline & $\begin{array}{l}\text { Demand price- } \\
\text { elasticity }\end{array}$ & $(-)$ \\
\cline { 2 - 3 } Moral Hazard & Complementary & $(-)$ \\
\cline { 2 - 3 } & Cheap substitutes & $(-)$ \\
\hline
\end{tabular}

Table $\mathbf{2 b}$. Economic arguments for categorizing coverage as mandatory (voluntary).

\section{Mandatory \\ Coverage}

\section{Economic Arguments}

\begin{tabular}{lll}
\hline \multirow{2}{*}{ Free Riding } & Income & $(-)$ \\
\cline { 2 - 3 } & $\begin{array}{l}\text { Type of } \\
\text { health risk }\end{array}$ & $(+)$ \\
& Income & $(-)$ \\
\cline { 2 - 3 } & Type of & $(+)$ \\
\hline $\begin{array}{l}\text { Transaction costs of Foresight } \\
\text { alternative ways of } \\
\text { organizing cross- } \\
\text { subsidies }\end{array}$ & & \\
\hline
\end{tabular}


Policy makers may weight the effects of the different factors when deciding whether a service may be classified as basic or supplementary, and whether coverage should be mandatory or voluntary.

\section{$\underline{\text { References }}$}

Aaron H. Should public policy seek to control growth of health care spending? Health Affairs, 2003; web exclusive.

Anderson LR, Mellor JM, \& Milyo J. Social Capital and Contributions in a Public Goods Experiment. Working Paper Series: 2003; 17. The Harris School, University of Chicago.

Arrow KJ. Uncertainty and the welfare economics of medical care. American Economic Review, 1963; 53 (5): 940-73.

Baker L, Birnbaum H, Geppert J, Mishol D, \& Moyneur E. Health Affairs, 2003; web exclusive.

Bannerjee AV. Envy. In: Dutta N, Gangopadhyay S, Mookerjee D \& Ray D (Eds.), Economic Theory and Policy: Essays in Honor of Dipak Bannerjee, Oxford University Press; 1990: pp. 91-111.

Brunner EJ. Free Riders or Easy Riders?: An Examination of the Voluntary Provision of Public Radio, Public Choice 1998; Springer, vol. 97(4), pages 587-604.

Cochrane JH. Time-consisted health insurance. Journal of Political Economy; 1995: 103 (3), 445-473.

Choi YB. Envy, Paradigms and Conventions: Uncertainty, Decision Making and Entrepreneurship. University of Michigan Press, Ann Arbor, MI; 1993: 125-147.

Colombo F, Tapay N. Private health insurance in Ireland: a case study. OECD Health Working Paper 2004; NO.10, DELSA/ELSA/WD/HEA.

Culyer AJ, \& Simpson H. Externality models and health: a 'Rückblick' over the last twenty years. Economic Record, 1980; 56, 522-530.

Cutler DM. Equality, efficiency and market fundamentals: the dynamics of international medical-care reform. Journal of Economic Literature 2002; Vol XL: 881906. 
Cutler DM \& Zeckhauser. The Anatomy of Health Insurance. In: Culyer AJ \& Newhouse JP (Eds.) Handbook of Health Economics, Elsevier, Amsterdam: The Netherlands; 2000: (1A), 563-644.

Cutler DM \& Gruber J. Does public insurance crowd out private insurance? Quarterly Journal of Economics; 1996: 111, 391-430.

Diamond P. Organizing the health insurance market. Econometrica, 1992; 60 _6., 1233-1254.

Drummond MF, O’Brien B, Stoddart GL, \& Torrance GW. Methods for Economic Evaluation of Health Care Programmes. New York, Oxford University Press, 1997.

Drummond MF, \& McGuire A. Economics Evaluation in Health Care: Merging Theory with Practice, Oxford: Oxford University Press, 2001.

Duesenberry J. Income, Savings and the Theory of Consumer Behavior. Harvar University Press, Cambridge, MA; 1949.

Duncan O. Does money buy satisfaction? Social Indicators Research; 1975-76: 2, $267-$ 274.

Dubay L. \& Kenny G. Did Medicaid expansions for pregnant women crowd out private coverage? Health Affairs,; 1997: 16(1), 185-93.

Easterlin R. Will raising the incomes of all increase the happiness of all? Jounrnal of Economic Behavior and Organization; 1995: 27, 35-47.

Elster J. Envy in social life. In Zeckhauser RJ (Ed.), Strategy and Choice, MIT Press, Cambridge, MA; 1991: 49-82.

Evans RG. Universal access: the Trojan horse. In The Professions and Public Policy, eds. Slayton P, \& Trebilcock MJ, 1978; pp. 191-208. Toronto: University of Toronto Press.

Feldstein PJ. Health care economics. 5th ed. Albany, NY: Delmar; 1999.

Frank RH. The demand for unobservable and other nonpositional goods. American Economic Review; 1985: 75, 101-116.

Frank RH. Positional externalities. In: Zeckhauser RJ (Ed.), Strategy and Choice, MIT Press, Cambridge, MA; 1991 pp. 25-47.

Frank RH. Luxury Fever. New York: Free Press; 1999.

Fuchs VR. Time preference and health: an explanatory study, in: VR Fuchs (ed.), Economic aspects of health, University of Chicago Press, Chicago; 1982: 93-120.

Galbraith JK. The affluent Society. Houghton Mifflin, Boston, MA; 1958. 
Garber AM. Advances in cost-effectiveness analysis of health interventions. Handbook of Health Economics, 2000; 1: 181-221. Edited by Culyer AJ \& Newhouse JP. Elsevier Science BV.

Goddard M, Hauck K, Preker A, Smith PC. Priority setting in health - a political economy perspective. Health Economics, Policy and Law 2006; 1 (1): 79-90.

Graaff JV. Theoretical Warfare Economics. London: Cambridge University Press, 1971.

Gruber J. Public Finance and Public Policy. Worth Publishers, 2005.

Harris A, Buxton M, O'Brien B, Rutten F, \& Drummond M. Using economic evidence in reimbursement decisions for health technologies: experience of 4 countries. Expert Review of Pharmacoeconomics \& Outcomes Research 2001; 1: 7-12. www.future-drugs.com.

Hauck K, Smith PC, \& Goddard M. The Economics of Priority Setting for Health: A Literature Review, Washington, DC: World Bank, 2003.

Hirsch, F. Social Limits to Growth. Harvard University Press, Cambridge, MA; 1976.

Holahan J. Crowding out: How big a problem? Health Affairs; 1997: 16(1), 204-06.

Hughes D, Tunnage B, \& Yeo S. Drugs for exceptionally rare diseases: do they deserve special status for funding? QJM 2005; 98 (11): 829-836.

Johannesson M. Should we aggregatevrelative or absolute changes in QALYs? Health Economics 2001; 10: 573-577.

Johnson RW \& Crystal S. Uninsured status and out-of-pocket costs at midlife. Health Services Research; 2000: 35(5) (Part I): 911-32.

Kahneman D \& Tversky A. Prospect Theory: An Analysis of Decision Under Risk. Econometrica; 1979: 47, 263-91.

Kapteyn A \& Wansbeek T. The individual welfare function: A review. Journal of Economic Psychology; 1985: 6, 333-363.

Kooijman H. PharMerit. Zorg Verzekerd: Internationaal vergelijkend onderzoek naar de samenstelling van het basispakket van de nationale ziektekostenverzekering. 2003.

Kotlikoff L, \& Hagist C. Who's Going Broke? Comparing Growth in Healthcare Costs in Ten OECD Countries. http:// papers.nber.org/papers/W11833 (2005).

Mehrez A, \& Gafni A. Healthy-years equivalents versus quality-adjusted life years: in pursuit of progress. Medical Decision making, 1993; 13: 287-292. 
Mehrez A, \& Gafni A. Quality-adjusted life years, utility theory, and healthy-years equivalents. Medical decision making, 1989; 9: 142-149.

Nath SK. A Reappraisal of Welfare Economics. London: Routledge \& Kegan Paul, 1969.

Neumark D \& Postlewaite A. Relative income concerns and the rise in married women's employment. University of Pennsylvania, Center for Analytic research in Economics and Social Science, 1993. Working Paper, 93-17.

Newhouse JP. Cream skimming asymmetric information, and a competitive insurance market. Journal of Health Economics; 1984: 3, 97-100.

Newhouse JP. Medical care costs: how much welfare loss?, Journal of Economic Perspectives 1992; 6 (3), 3-21.

Newhouse JP. An iconoclastic view of health cost containment. Health Affairs 1993; 12 (suppl): 152-171.

Nord E. Cost-value analysis in health care: making sense out of QALYs. Cambridge, Cambridge University Press, 1999.

Nord E. Concerns for the worse off: fair innings versus severity. Social Science and Medicine 2005; 60: 257-263.

Nord E, Pinto JL, Richardson J, Menzel P, Ubel P. Incorporatine societal concerns for fairness in numerical valuations of health programmes. Health Economics 1999; 8: 25-39.

Nyman JA. The Theory of Demand for Health Insurance. Stanford, California: Stanford University Press, 2003.

Organisation for Economic Co-operation and Development. Health Data 2002. OECD, www.oecd.org.

Palfrey TR, \& Prisbrey JE. Anomalous behaviour in public goods experiments: how much and why?. American Economic Review 1997; 87, 829-46.

Pauly MV. Overinsurance and public provision of insurance: the roles of moral hazard and adverse selection, Quarterly Journal of Economics; 1974: 88, 44-62.

Pauly MV. Risk variation and fallback insurers in universal coverage insurance plans. Inquiry; 1992: 29, 137-147.

Reinhardt UE. Abstracting from distributional effects, this policy is efficient. In Health, Health Care and Health Economics: Perspectives on Distribution, edited by Barer ML, Getzen TE, \& Stoddart GL. New Yoork: John Wiley, 1998.

Rice T. The Economics of Health Reconsidered. Chicago, Health Administration Press, 2003. 
Samuelson PA. Foundations of Economic Analysis. New York: Atheneum, 1947.

Schut FT \& Laper' RM. Dilemma's bij financiering van preventieve gezondheidszorg (Dilemmas concerning financing preventive gezondheidszorg (The economics of preventive health care), De Tijdstroom, Lochem; 1988: 34-66.

Schut FT. Competition in the Dutch health care sector. Rotterdam: Proefschrift (PhD Thesis) Erasmus Universiteit Rotterdam, 1995.

Smith C, Cowan C, Heffler S, \& Catlin A. National health spending in 2004: recent slowdown led by prescription drug spending. Health Affaris, 2006; 25 (1):186-196.

Solnick S.J. \& Hemenway D. Is more always better?: A survey on positional concerns. Journal of Economic Bahevioue \& Organization 1998; Vol. 37: 373-383.

Stolk EA, Brouwer WBF \& Busschbach JJV. Rationalising retioning: economic and other considerations in the debate about funding of Viagra. Health Policy 2002; 59 (1): 53-63.

Stolk EA, Pickee SJ, Ament AHJA \& Busschbach JJV. Equity in health care prioritization; an empirical inquiry into social value. Health Policy 2005; 74 (3): 34355.

Stolk EA \& Poley MJ. Criteria for determining a basic health services package. Recent developments in the Netherlands. European Journal of Health Economics 2005; 6 (1): 2-7.

Stolk EA, van Donselaar G, Brouwer WBF, Busschbach JJV. Reconciliationof economicconcerns and health policy: illustration of an equity adjustment procedure using proportional shortfall. PharmacoEconomics 2004; 22 (17): 1097-1107.

Thomas K 1994/5. Are subsidies enough to encourage the uninsured to purchase health insurance: An analysis of underlying behavior. Inquiry, 31: 415-24.

van den Berg J, Janssen R, \& Haveman HB. Solidariteitsvoorkeuren ten aanzien van ziektekostenverzekering. (Solidarity preferences regarding health insurance, 1985). Netherlands Central Bureau of Statistics, Monthly Bulletin of Health Statistics, 1986; $5(8), 5-29$.

van Doorslaer E, \& Schut FT. Vraag naar gezondheidszorg. In Algemene economie van de gezondheidszorg. Edited by Lapre' R, Rutten S, Schut FT. Elsevier, 1999.

Van de Ven WPMM. Choices in health care: a contribution from the Netherlands. British Medical Bulletin 1995; 1995: 51(4), 781-790.

van de Ven WPMM \& Ellis RP. Risk adjustment in competitive health plan markets. In AJ Culyer \& JP Newhouse (Eds.), Handbook of Health Economics, Elsevier, Amsterdam: The Netherlands; 2000: (1A); 755-846,

Veblen T. The Theory of the Leisure Class. MacMillan, New York; 1899. 
Williams A. Intergenerational equity: an exploration of the 'fair innings' argument. Health Economics 1997; 6 (2): 117-32.

Wolf N. The Beauty Myth. William Morrow, New York; 1991. 